\title{
CORRELATION BETWEEN THE PRESENCE OF ANDROGENIC RECEPTORS AND MOLECULAR AND HISTOPATHOLOGICAL VARIABLES IN BREAST CANCER
}

Beatriz Baaklini Geronymo1, Filomena Marinho Carvalho², Adriana Akemi Yoshimura', Juliana Zabukas de Andrade$^{1}$, Danúbia Ariana Andrade ${ }^{1}$, Alfredo Carlos Simoes Dornelas de Barros ${ }^{1}$

${ }^{1}$ Clínica Prof Alfredo Barros; Laboratório Filomena Carvalho - São Paulo (SP), Brazil.

${ }^{2}$ Laboratório Filomena Carvalho - São Paulo (SP), Brazil.

Introduction: The expression of androgenic receptors (AR) is a new predictive marker of response and prognosis in invasive breast carcinoma (BC). It emerges as a potential therapeutic target. Objective: To evaluate the frequency of AR positivity and its correlation with molecular and histopathological parameters in infiltrative BC. Method: Retrospective cohort study, analyzing 119 cases of invasive non-metastatic BC, seen at a private clinic. Hormonal receptors were screened by immunohistochemical reaction, and AR were considered positive when present in at least $10 \%$ of cells, ER and PR from $1 \%$. This finding was correlated with pathological staging, histological grade (HG), vascular-lymphatic invasion (VLI), estrogen (ER) and progesterone receptors (RP), HER2 and Ki 67. Results: Androgen receptors were positive in $80.6 \%$ of cases. In the assessment of pathological staging, of the 63 patients with stage I, 81\% showed positive androgen receptors, while among the 28 patients with stage II, $75 \%$ had positive androgen receptors, and $88 \%$ of the 17 patients with stage III presented the positivity of the recipient. Regarding the histological parameters of the tumor, 16 patients had grade 1 tumors, 93.7\% of them with positive androgen receptors, while among the 63 with grade 2 tumors $90.4 \%$ had androgen receptor positivity, and only $59,3 \%$ of the 27 tumors evaluated as grade 3 had a positive androgen receptor. The vascular-lymphatic invasion was negative in 57 patients, $78.9 \%$ of the tumors with positive androgen receptor. Among the 56 tumors with positive vascular-lymphatic invasion, $85.7 \%$ had an androgen receptor positivity. In the immunohistochemical evaluation of tumors, among the 95 patients with positive estrogen receptors, 91.5\% also had positive androgen receptor, which was positive in only $37.5 \%$ of the 24 patients with negative estrogen receptors. Of the 21 patients who had tumors with overexpressed HER, $85.7 \%$ also had positive androgen receptors, which were also positive in $86.4 \%$ of 96 without overexpression of HER2. In the evaluation of cell proliferation by the Ki67 antigen, among the 50 tumors with Ki67 $<20 \%$, 94\% had positive androgen receptors, while $83.7 \%$ were positive among the 49 tumors with Ki67 between 20 and $50 \%$ and only $35 \%$ positivity of androgen receptors in 17 tumors with Ki67> 50\%. Conclusions: AR positivity is associated with more differentiated hormone-dependent tumors with a lower proliferation rate. 